\title{
Application of atmospheric pressure cold plasma to sanitize oak wine barrels
}

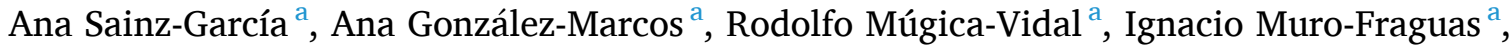

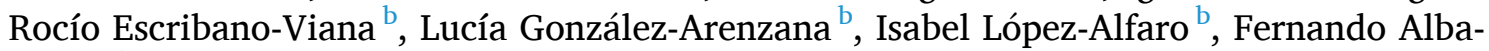 \\ Elías $^{\text {a, }}$, Elisa Sainz-García ${ }^{\text {a }}$ \\ a Department of Mechanical Engineering, University of La Rioja, C/ San José de Calasanz 31, 26004 - Logroño, La Rioja, Spain \\ ${ }^{\mathrm{b}}$ Instituto de Ciencias de La Vid y Del Vino (ICVV), Gobierno de La Rioja, Universidad de La Rioja, Consejo Superior de Investigaciones Científicas, Finca La Grajera, \\ Ctra. de Burgos Km. 6, 26007 - Logroño, La Rioja, Spain
}

\section{A R T I C L E I N F O}

\section{Keywords:}

Atmospheric pressure cold plasma

Barrel sanitization

P. pentosaceus

A. pasteurianus

B. bruxellensis

\begin{abstract}
A B S T R A C T
Oak wood barrel sanitization is crucial in terms of food safety, since barrels enrich the wine in aromas and taste sensation and provide physico-chemical stability. The most used method is barrel sulphuring; however, there is a European prohibition (Directive 98/8/CE2) that does not allow the use of this method. For this reason, the aim of the present work was to study an alternative technology, the atmospheric pressure cold plasma (APCP) to sanitize oak wood staves. Three wine spoilage microorganisms, two bacteria (Pediococcus pentosaceus and Acetobacter pasteurianus) and a yeast (Brettanomyces bruxellensis), were inoculated in the wood staves. Then, they were exposed to APCP device at a 12-passes treatment with different plasma powers ( $90 \mathrm{~W}$ and $500 \mathrm{~W}$ ) and plasma gases (air, nitrogen and argon). A total inactivation of the yeast was achieved after the air and nitrogen plasma treatments, being the most sensitive microorganism to the APCP. In terms of bacteria, P. pentosaceus and A. pasteurianus showed a lower inactivation with respect to their controls. The reactive oxygen and nitrogen species generated during the plasma generation process seem to play the main role on the microbial inactivation. Finally, no morphological modifications on the wood surface were identified after APCP treatments.
\end{abstract}

\section{Introduction}

Over the last years, the competitiveness of the wine market has been increased as a result of the increment in consumers who ask for quality wines. To deal with this, wine industry has improved not only manufacturing conditions but also food security and safety without forgetting the traditional character that makes each wine special.

Oak wood barrel using is considered as one of the most important steps in production and ageing processes of wine, since it takes a crucial role in its final organoleptic attributes. During barrel ageing, the winewood exchanges enrich the product in aromas and taste sensation. In addition to this, micro-oxygenation occurs, which leads to a physical and chemical stability in the product and gives it the delicacy, balance and aromatic complexity so appreciated by consumers. Furthermore, barrel re-using provides unique properties to wine and alcoholic beverages at low cost, so that its preservation is vital. However, the hefty price and the difficulties in maintenance of wood barrels make their reusing necessary (García-Alcaraz et al., 2020).

Nevertheless, care must be taken with barrel re-using due to the microbiological and chemical contamination that could be appear since cleansing and disinfection of wood barrels are tough. On the one hand, wood has a porous structure that facilitates the wine penetration up to 8 $\mathrm{mm}$ and the microbial transport into the cracks and crevices of staves (Eveline J. Bartowsky \& Henschke, 2008; Suárez, Suárez-Lepe, Morata, \& Calderón, 2007). That fact appeals to wine spoilage microorganisms such as Brettanomyces bruxellensis (B. bruxellensis), acetic acid bacteria (AAB) and lactic acid bacteria (LAB) (E. J. Bartowsky, 2009; Costantini, Cersosimo, Del Prete, \& Garcia-Moruno, 2006; Ribéreau-Garyon, Glories, Maujean, \& Dubourdieu, 2006). Particularly, barrel ageing has been identified as the most prone stage to be contaminated by

\footnotetext{
* Corresponding author.

E-mail addresses: ana.sainz@unirioja.es (A. Sainz-García), ana.gonzalez@unirioja.es (A. González-Marcos), rodolfo.mugica@unirioja.es (R. Múgica-Vidal),

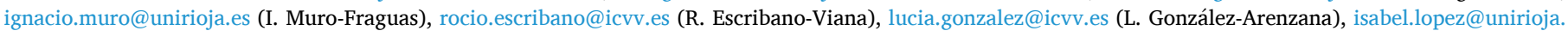
es (I. López-Alfaro), fernando.alba@unirioja.es (F. Alba-Elías), elisa.sainzg@unirioja.es (E. Sainz-García).
} 
B. bruxellensis, producing metabolites and processes that have a detrimental effect on the final quality of the wines (Falguera, Forns, \& Ibarz, 2013; González-Arenzana et al., 2013; Schmid, Grbin, Yap, \& Jiranek, 2011). Some of these processes are the synthesis of volatile phenols, the biogenic amines formation or the increase of volatile acidity, specially affecting wines which spend time in ageing barrels (Palacios, Borinaga, \& Carrillo, 2012). On the other hand, during wine ageing, tartrate is produced, which can attach to barrel walls and give shelter to contaminating microorganisms (Palacios et al., 2012).

Nowadays, the most widely used methods for barrel decontamination rely on applying chemical additives and physical processes. Regarding the chemical methods, the most applied one is barrel sulphuring, which is based on burning sulphur pills inside empty barrels. When the combustion takes places, sulphur dioxide is produced, which has biocidal effects on wood. However, Directive 98/8/CE2 of the European Commission prohibits the use of sulphur dioxide for the sanitization of barrels and a moratorium of this directive, which ends in 2022, exists in Spain (Palacios et al., 2012). The abovementioned has led to investigate alternative technologies (ozone, hydrogen peroxide, ultrasounds, microwaves, thermal treatments, etc.) that allow the task to be viable, from an economic and operational point of view, guaranteeing effective sanitization (González-Arenzana et al., 2013; Guzzon et al., 2017; Marko et al., 2005; Porter, Lewis, Barnes, \& Williams, 2011; Schmid et al., 2011). Moreover, these technologies should affect the implicit characteristics of wood as little as possible because of the contribution of wood to organoleptic and physical properties of the final wine (Stadler, Schmarr, \& Fischer, 2020). Nevertheless, those methods have some disadvantages related to the high cost, adverse health effects for the manipulator or problems with porosity of wood (Costantini et al., 2016). With a view to fulfilling consumer's expectations of food products related to adequate shelf life, reasonable costs and healthy properties, it is essential to adopt novel processing technologies or even make changes on traditional ones (Clodoveo, Dipalmo, Rizzello, Corbo, \& Crupi, 2016). In this context, the use of atmospheric pressure cold plasma (APCP) technology could be an alternative for solving the aforementioned problems.

Atmospheric pressure cold plasma has been a focus of increased research in recent years since it is referred to a non-equilibrated, ionized gas generated at ambient temperature and atmospheric pressure. During the process different energetic species such as free electrons and radicals, positive and negative ions, neutral and excited atoms, molecules and ultraviolet (UV) photons are found (Scholtz, Pazlarova, Souskova, Khun, \& Julak, 2015). To date, reactive oxygen species (ROS) and reactive nitrogen species (RNS) are believed to be the main molecules responsible for biological effects of APCP (Iuchi et al., 2018). In addition, this technology offers some advantages in comparison with other methods. Firstly, APCP is a safe and cheap technology because it only consumes compressed air and electricity to generate the plasma in many cases. Secondly, auxiliary facilities are no required due to the generation at atmospheric pressure and ambient temperature. Finally, it is respectful with the environment as no toxic or waste chemicals are produced and few resources are needed.

Related to the improvement of non-thermal food processing technologies, a recent application of APCP for agrifood decontamination has been carried out (Misra, Yepez, Xu, \& Keener, 2019). In addition to this, a considerable literature has been published on the application of this technology with other purposes: enzymatic inactivation, improving the cooking quality of rice varieties, starch modifications or enhancing the seed germination (Lotfy, Al-Harbi, \& Abd El-Raheem, 2019; Paixão, Fonteles, Oliveira, Fernandes, \& Rodrigues, 2019; Tolouie, Mohammadifar, Ghomi, Yaghoubi, \& Hashemi, 2018; Yodpitak et al., 2019).

On the one hand, the direct APCP treatment is a known technology for food disinfection without the loss of its organoleptic or physicochemical properties. It should be noted that both the equipment and the parameters for obtaining plasma used by the different research groups are extremely variable, which make it difficult to compare the results.
However, many researchers have defined APCP as an adequate technique to improve the microbiological quality of a wide range of foods, both of vegetable and animal origin. Related to meat industry, several studies have been carried out with the aim of investigating inactivation of different bacteria such as Listeria monocytogenes, Listeria innocua, Salmonella typhimurium, Campylobacter jejuni or even moulds and yeasts (Lee et al., 2011; Misra \& Jo, 2017). The biocidal effect of APCP on other foods has also been reported. For instance, $15 \mathrm{~min}$ treatment with plasma air gas leads to a reduction of 5.53 logarithmic units in Colony Forming Units (CFU)/egg of Salmonella enteritidis for egg surface (Wan, Chen, Pankaj, \& Keener, 2017). Also, when Escherichia coli, L. monocytogenes and $S$. typhimurium were inoculated in milk samples and treated for $10 \mathrm{~min}$ with plasma, it resulted in a reduction of CFU/mL by approximately 2.40 logarithmic units. (Kim et al., 2015). In other works, reductions of E. coli, S. typhimurium and L. monocytogenes in slice cheese and cheddar and also $S$. enteritidis on surface of unpeeled almonds were studied (Hertwig et al., 2017; Yong, Kim, Park, Alahakoon, et al., 2015; Yong, Kim, Park, Kim, et al., 2015). In terms of vegetables, strawberries, bell peppers, tomatoes, onions, mandarins or groundnuts are some of the food matrices investigated (Chizoba Ekezie, Sun, \& Cheng, 2017; Misra et al., 2014; Ziuzina, Patil, Cullen, Keener, \& Bourke, 2014).

On the other hand, studies related to the inactivation of food contact surfaces through APCP technology have been reported. In a recent study, reductions of Plaque-Forming Units (PFU)/mL of a human norovirus (3.89 logarithmic units) and hepatitis A virus (2.02 logarithmic units) were achieved after the application of APCP treatment during $300 \mathrm{~s}$ over a stainless steel surface (Park \& Ha, 2018). Furthermore, significant reductions on PET surface of almost 5 logarithmic units of Bacillus subtilis endospores by $5 \mathrm{~s}$ of APCP treatment and 2.6 logarithmic units for Aspergillus niger conidiospores with $7 \mathrm{~s}$ of treatment were obtained (Muranyi, Wunderlich, \& Heise, 2008). Moreover, other authors inoculated E. coli and Staphylococcus epidermidis in stainless steel, silicone and PET surfaces. After 5 min of plasma treatment, they achieved reductions around 2.72, 4.43 and 3.18 logarithmic units of $\mathrm{CFU} / \mathrm{mL}$ in E. coli and 3.76, 3.19, 2.95 logarithmic units of $\mathrm{CFU} / \mathrm{mL}$ for S. epidermidis, on stainless steel, silicone and PET, respectively ( Dasan, Onal-Ulusoy et al., 2017). In fact, two recent reviews cite most of the investigations carried out about cleaning different food contact surfaces (glass slides, aluminium foil, paper cups, stainless steel, PET, PE) through APCP (Kart, 2018; Mandal, Singh, \& Pratap Singh, 2018).

To our knowledge, there are no documented studies on the efficacy of APCP treatments inactivating microorganisms on wood. Nevertheless, it could be a development field, since this technology might offer advantages in food processing, producing safer and higher quality products or even reducing energy costs. Therefore, the aim of the present study was to evaluate the inactivation effectiveness of the novel technology APCP for the LAB of the species Pediococcus pentosaceus, for the AAB of the species Acetobacter pasteurianus and for the yeast of the species Brettanomyces bruxellensis on the surface of oak wood used in winemaking as an effective and sustainable alternative with respect to technologies currently used for barrel sanitization.

\section{Materials and methods}

\subsection{Microbial strains, culture and sample preparation}

This study was carried out with three wine spoilage microorganisms, using strains from Spanish Type Culture Collection (CECT): a LAB (Pediococcus pentosaceus CECT 923), an AAB (Acetobacter pasteurianus CECT 824) and a yeast (Brettanomyces bruxellensis CECT 11045).

Pediococcus pentosaceus ( $P$. pentosaceus) was grown in Man Rogosa Shape (MRS) (De Man, Rogosa, \& Sharpe, 1960) broth in an incubator at $28^{\circ} \mathrm{C}$ for $48 \mathrm{~h}$; Acetobacter pasteurianus (A. pasteurianus) was cultured in Mann broth (25 g/L D-mannitol, $3 \mathrm{~g} / \mathrm{L}$ peptone, $5 \mathrm{~g} / \mathrm{L}$ yeast extract) at $25^{\circ} \mathrm{C}$ for $48 \mathrm{~h}$ and Brettanomyces bruxellensis (B. bruxellensis) was grown in Glucose Yeast Peptone (GYP) broth $(20 \mathrm{~g} / \mathrm{L}$ glucose, $5 \mathrm{~g} / \mathrm{L}$ yeast 
extract, $5 \mathrm{~g} / \mathrm{L}$ peptone) at $28{ }^{\circ} \mathrm{C}$ for $48 \mathrm{~h}$. After incubation, when the cultures reached stationary phase $\left(10^{8}-10^{9}\right.$ Colony Forming Units $\left./ \mathrm{mL}\right)$, cells of each strain were collected by centrifugation at $10000 \times g$ at $4{ }^{\circ} \mathrm{C}$ for $30 \mathrm{~min}$. The pellet obtained was resuspended in $50 \mathrm{~mL}$ of saline solution $(0.9 \% \mathrm{NaCl})$ and inoculated in $450 \mathrm{~mL}$ of sterile synthetic wine (yeast extract $4 \mathrm{~g} / \mathrm{L}$, glycerol $2 \mathrm{~g} / \mathrm{L}$, DL-Malic $6 \mathrm{~g} / \mathrm{L}$, ethanol $100 \mathrm{~mL} / \mathrm{L}$ ).

Fragments of $50 \times 30 \times 10 \mathrm{~mm}$ of oak staves with a medium toasted degree were used as samples. The staves were sterilized at $121^{\circ} \mathrm{C}$ and 1 bar for $20 \mathrm{~min}$ prior to contamination with the cultures prepared in synthetic wine. Samples per triplicate were contaminated by immersion in each of the cultures for $48 \mathrm{~h}$ in an orbital shaker (100 rpm) at $27^{\circ} \mathrm{C}$.

\subsection{Atmospheric pressure cold plasma treatment}

An APCP equipment PlasmaSpot ${ }^{\circledR}$ (MPG, Luxenburg) with a dielectric barrier discharge was used in the present study (see Fig. 1). It consists of two coaxial electrodes, with an $\mathrm{Al}_{2} \mathrm{O}_{3}$ dielectric tube between them. The inner electrode is grounded and the external one is connected to a high voltage source operating at $68 \mathrm{kHz}$. The plasma was generated with three different gases: compressed air, nitrogen (99.999\%) and argon (99.999\%) at a flow of $80 \mathrm{slm}, 80 \mathrm{slm}$ and $40 \mathrm{slm}$, respectively. The plasma power was $500 \mathrm{~W}$ for air and nitrogen and $90 \mathrm{~W}$ for argon.

Batches of three oak wood samples were exposed to the APCP device at a 12-passes treatment. In each batch, one of the three microorganisms was under study. During these treatments, the plasma device was moved across the surface of the oak wood staves with a scanned movement as can be observed in Fig. 1 [c]. A linear speed of $100 \mathrm{~mm} / \mathrm{s}$, a pitch of $4 \mathrm{~mm}$ and a gap of $10 \mathrm{~mm}$ were the movement parameters used. Table 1 shows the plasma conditions for each batch of treatments.

\subsection{3. Study of microbial inactivation}

When plasma treatments were finished, each treated and untreated staves of oak wood was brushed with an automatic wood planer reaching a deep of $1 \mathrm{~cm}$. The chips gathered in sterile plastic bags were weighted and then $300 \mathrm{~mL}$ of sterile Trypticasein Soy Broth (TSB, Conda, Madrid, Spain) recovering medium was added. Sealed bags were
Table 1

Conditions of the plasma treatments.

\begin{tabular}{lllll}
\hline Sample label & Plasma Gas & Gas Flow (slm) & Cooling gas & Plasma Power (W) \\
\hline $\mathrm{CT}$ & - & - & - & - \\
$\mathrm{Ar}$ & Argon & 40 & Air & 90 \\
$\mathrm{~N}_{2}$ & Nitrogen & 60 & Air & 500 \\
Air & Air & 60 & Air & 500 \\
\hline
\end{tabular}

incubated at $25{ }^{\circ} \mathrm{C}$ in an orbital shaker at $100 \mathrm{rpm}$ for $24 \mathrm{~h}$. After incubation, the liquid was recovered and centrifuged (10000 rpm; $30 \mathrm{~min}$; $\left.4{ }^{\circ} \mathrm{C}\right)$.

The samples obtained were serially diluted and spread on different culture media plates. Samples from staves contaminated with $P$. pentosaceus were spread on MRS plates and incubated at $28^{\circ} \mathrm{C}$, staves contaminated with $A$. pasteurianus were spread in Mann plates and incubated at $25{ }^{\circ} \mathrm{C}$ and samples from staves contaminated with B. bruxellensis were spread in GYP and incubated at $28{ }^{\circ} \mathrm{C}$. After an incubation period of $48 \mathrm{~h}$, colonies were counted in plates with growth between 30 and 300 colonies and expressed in each sample as the average CFU per gram of wood with the corresponding standard deviation, represented by error bars. All microbiological analyses were conducted in triplicate for each experiment.

\subsection{Thermal characterization}

Wood sample surface temperatures were monitored using a K-type Teflon-coated thermo couple connected to a data logger Testo 167T4. Probes were attached to the sample surface and temperatures were recorded every $1 \mathrm{~s}$ while samples were treated. In addition, a thermographic study was carried out with the aim of determining the maximum depth of the wood staves at which samples are affected by the temperature increase as a consequence of the plasma treatment. For this purpose, a thermal imaging camera TESTO 871 (Testo SE \& Co. KGaA, Germany) was used. The taken images were analysed with the software IRSoft (v4.3).
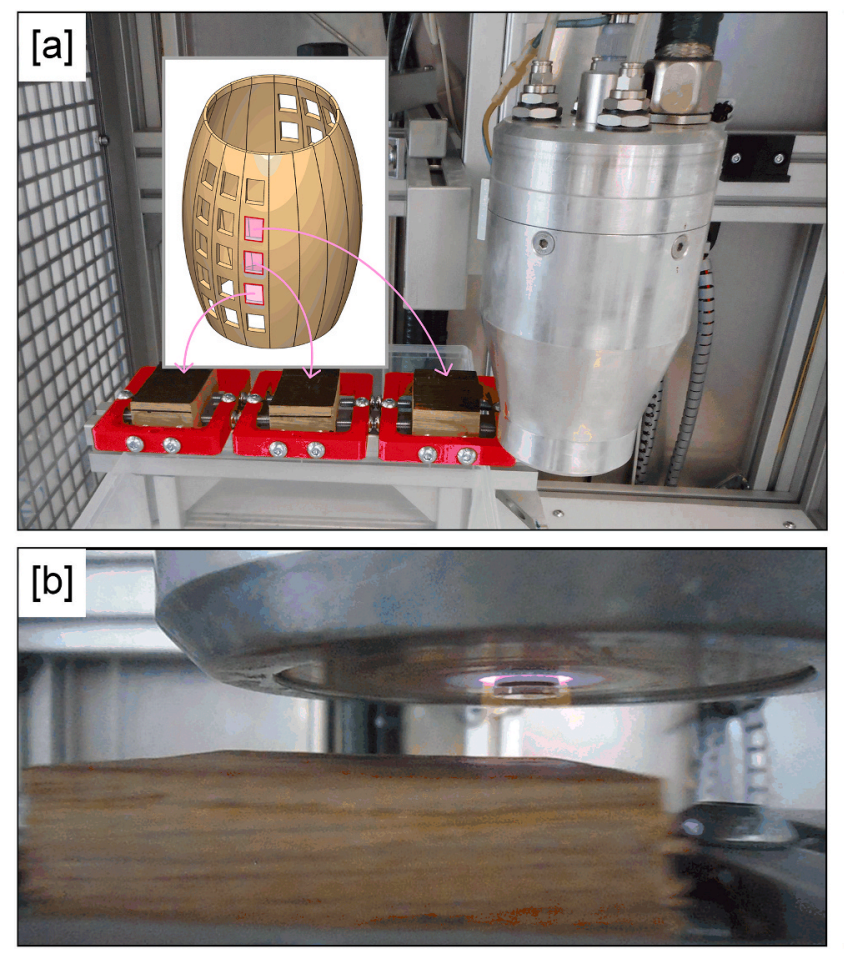

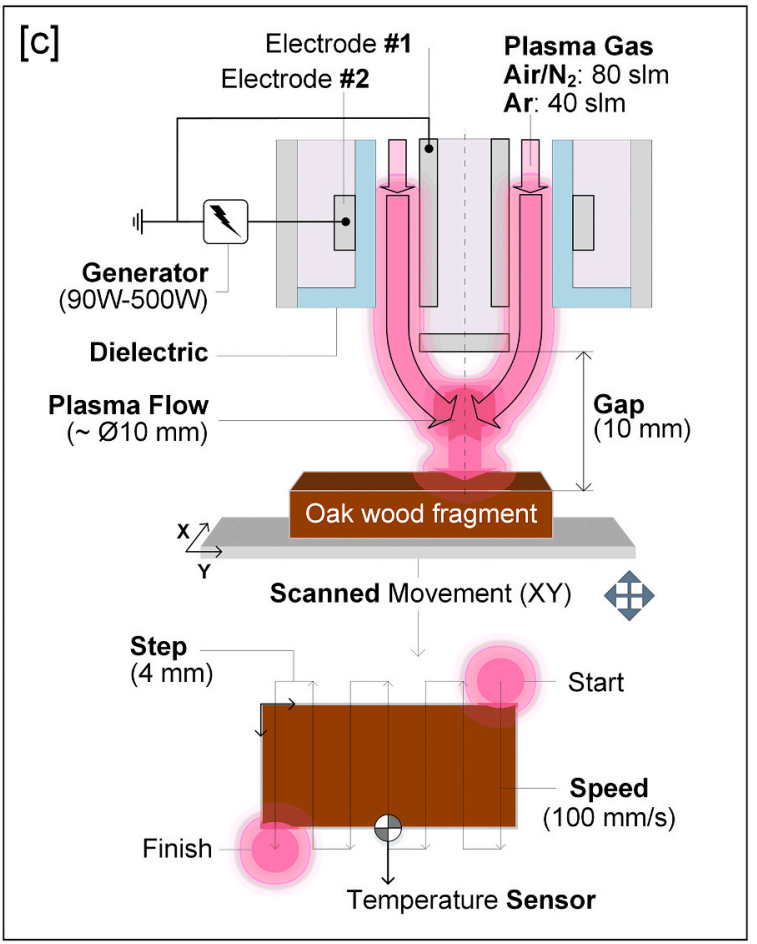

Fig. 1. [a] Plasma treatment process of oak wood samples; [b] Close view of plasma treatment process; [c] Scheme of plasma treatment process. 


\subsection{Morphological characterization}

A HITACHI S-2400 Scanning Electron Microscope (SEM) operating at $18 \mathrm{kV}$ was used to analyse the surface morphology of the treated and untreated wood staves. Sample surfaces were coated with a thin layer of palladium and gold using a plasma sputtering apparatus before the SEM examination to make them conductive.

\subsection{Statistical analysis}

Microbial inactivation results were analysed by Tukey's test with a level of significance of $p<0.05$. The program used for that purpose was Statgraphics Centurion XVII.II.

\section{Results and discussion}

It is known how important is the barrel disinfection to organoleptic and health characteristics of wine and therefore for wine quality (Guzzon et al., 2017). Next section discusses the results obtained in terms of microbial inactivation and wooden surface morphology after the application of the plasma treatments on the surface of the oak wood staves.

\subsection{Inactivation of microorganisms}

Fig. 2 shows microbial viable and cultivable (VC) population (log $\mathrm{CFU}$ ) achieved after each plasma treatment depending on the plasma gas used for each microorganism analysed. Fig. 2[a] provides the results obtained in the inactivation tests for $P$. pentosaceus. Regardless of the plasma gas, around 2 logarithmic units reduction of the population was observed after the 12-passes plasma treatment (from $8.33 \pm 0.08 \mathrm{log}$ $\mathrm{CFU} / \mathrm{g}$ wood in the control to $5.92 \pm 0.24 \mathrm{log} \mathrm{CFU} / \mathrm{g}$ wood, $6.46 \pm 0.5$ $\log \mathrm{CFU} / \mathrm{g}$ wood and $6.32 \pm 0.13 \mathrm{log} \mathrm{CFU} / \mathrm{g}$ wood for air, nitrogen and argon plasma, respectively) which explains there are no statistically significant differences $(p<0.05)$ between plasma gases used for those treatments. In regards to A. pasteurianus (see Fig. 2[b]), similar inactivation results were achieved for air plasma and nitrogen plasma (from $3.99 \pm 0.00$ in the control to $2.08 \pm 0.05 \mathrm{log} \mathrm{CFU} / \mathrm{g}$ wood and $1.99 \pm$ $0.06 \mathrm{CFU} / \mathrm{g}$ wood) showing no statistically significant differences between them. A lower inactivation effect was reached for the argon plasma treatment $(3.11 \pm 0.22 \log \mathrm{CFU} / \mathrm{g}$ wood). Finally, total inactivation of $B$. bruxellensis (see Fig. 2[c]) was identified after both air and nitrogen plasma treatments. However, a decrease of almost 3 logarithmic units was obtained with the argon plasma treatment $(2.57 \pm 0.14$ $\log \mathrm{CFU} / \mathrm{g}$ wood) which results in statistically significant differences between this plasma gas and the other two plasma gases. Hence, taking into account these results, it could be said that $B$. bruxellensis was the most sensitive microorganism to APCP treatments whichever the plasma gas used.

Up to our knowledge, this report is the first that investigates the effect of APCP on microbial inactivation over oak wood. Nonetheless, as it is said above, numerous studies have investigated the ability of APCP to inactivate microorganisms on other food or beverages contact surfaces. Indeed, differences in the inactivation degree have been found depending on the type and initial concentration of the microorganism analysed (Sedghizadeh, Chen, Schaudinn, Gorur, \& Jiang, 2012) and the process parameters (plasma power, plasma gas and plasma gas flow) (Liu, Chen, Yang, \& Zhou, 2008; Miao \& Jierong, 2009; Surowsky, Fröhling, Gottschalk, Schlüter, \& Knorr, 2014; Wiegand et al., 2013). It is also known that the characteristics and amount of the diverse biological active agents generated during the plasma generation process, such as reactive oxygen species (ROS), reactive nitrogen species (RNS), UV radiation, charged particles, electric field and heat are determined by the process parameters (Ehlbeck et al., 2011). The whole biological active agents and their synergic effect have been suggested as the most probable cause of the microbial reduction observed (Ehlbeck et al., 2011; Fridman, 2008).

Against this backdrop, some researchers have spent effort trying to identify the key causes of the microbial inactivation produced through APCP treatment describing ROS, RNS and UV radiation as the main ones (Niemira, 2012; Reineke, Langer, Hertwig, Ehlbeck, \& Schlüter, 2015). Nonetheless, the role of UV radiation is sometimes described as a controversial issue since some studies consider that a sufficiently high intensity is necessary to inactivate cells, and other authors observed that UV radiation can provoke lethal effects because of the cell membrane damage (Reineke et al., 2015).

In particular, the current work showed some differences between the achieved inactivation for each microorganism depending on the plasma gas applied. In fact, the dependence of the characteristics and concentrations of ROS and RNS generated during APCP treatments on the type of the plasma gas used is known (Schmidt-Bleker, Winter, Bösel, Reuter, \& Weltmann, 2015). The data illustrated by Fig. 2 indicate that the use of argon as plasma gas gets generally lower inactivation, so it could be said that it is the least effective treatment. This fact suggests a lower ROS and RNS generation, what is in accordance with the results of other research works in which lower concentrations of reactive species were identified in argon plasma in comparison with other gases such as air (Kondeti et al., 2018; Seo et al., 2010; Yoon et al., 2016). In this way, UV radiation is thought to be the main cause of microbial inactivation when using argon plasma while in the case of the air plasma the effect of the reactive species (ROS and RNS) seems to play the major role. Finally, for nitrogen plasma, the combination of both cited factors could result in a lethal cell damage (Choi et al., 2006; Mounir Laroussi, 2005).

Furthermore, when considering differences in microbial reductions
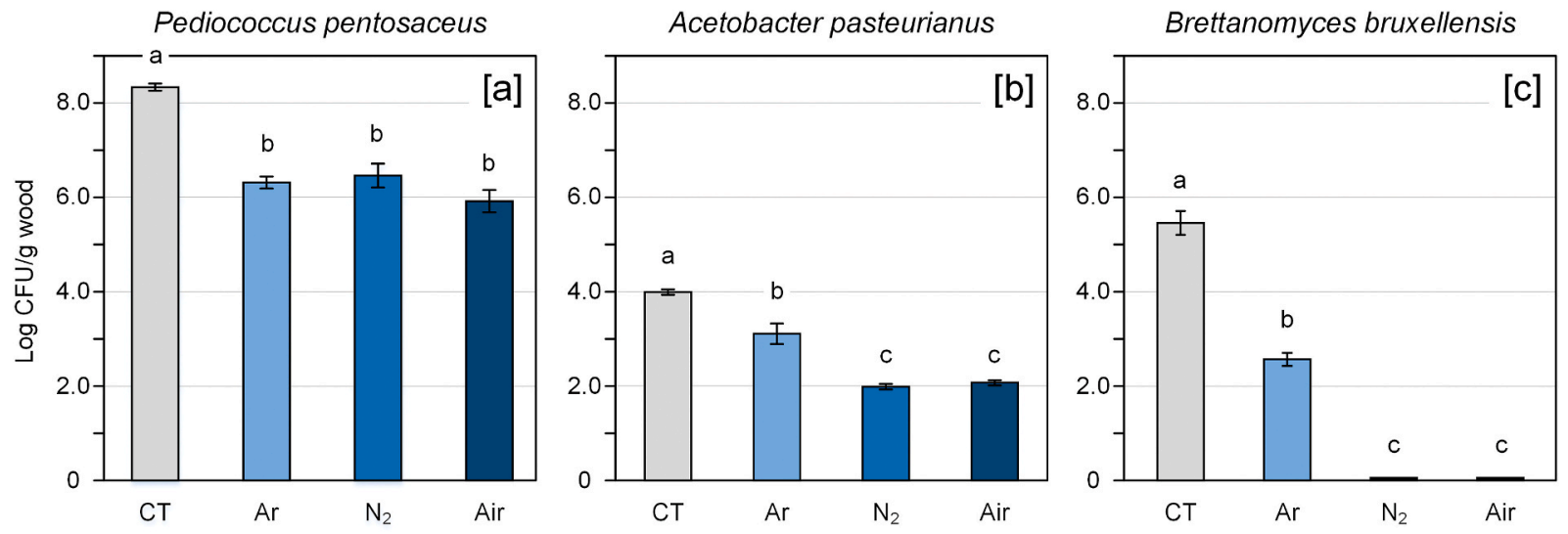

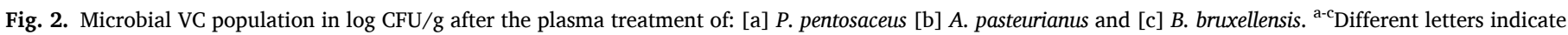
statistically significant differences $(\mathrm{p}<0.05)$. 
by APCP, the plasma power is worthwhile mentioning. A higher power (500 W) was set for air and nitrogen plasmas in comparison with argon plasma $(90 \mathrm{~W})$ and it resulted in a better inactivation. Therefore, the use of a more energetic plasma could lead to a higher disinfection efficiency (Feng et al., 2009).

Considering all these data, our results could suggest that the use of a less energetic plasma, which produces a lower concentration of reactive species, leads to a lower disinfection efficiency, having the UV radiation the main role in the inactivation.

No statistically significant differences were found between the inactivation achieved by air plasma and nitrogen plasma, what is in accordance with other authors' observations (Mošovská et al., 2019; Xiao et al., 2016). Indeed, a reduction of 2 logarithmic units was reached for both bacteria and of 5.5 logarithmic units for the yeast, regardless the gas used (see Fig. 2). On the contrary, other investigations found some differences which could be due to the concentration and characteristics of the reactive species generated depending on the plasma gas (Dasan, Boyaci, \& Mutlu, 2017; Hertwig et al., 2017; Niemira, 2012). On the one hand, they have proved that ROS enhance the plasma effectiveness, suggesting that the use of oxygen-containing gas mixes could be the most effective ones (Niemira, 2012). On the other hand, a higher concentration of reactive species are generated in air plasmas (Hertwig et al., 2017). However, as it is said above, in this work virtually no inactivation statistically significant differences were noted when using air or nitrogen plasma gases. This fact could be due to the sufficiently high concentration of ROS and RNS generated in the air plasma so that the inactivation could be achieved. Instead, with nitrogen plasma, although the reactive species seem to be generated to a lesser extent, their combination with UV radiation might give a similar lethal effect.

Not only the abovementioned reasons, but also the type of microorganism studied may influence the inactivation results. In this sense, there is dispute regarding the resistance of Gram + bacteria ( $P$. pentosaceus) and Gram-bacteria (A. pasteurianus) against plasma treatment. Some researchers described Gram-like the most susceptible ones (Choi et al., 2006; Mai-Prochnow, Murphy, McLean, Kong, \& Ostrikov, 2014; Sharkey, Chebbi, McDonnell, Staunton, \& Dowling, 2015). In contrast, other authors found the opposite (Nishime et al., 2017; Sedghizadeh et al., 2012). Nevertheless, there are investigators in whose results no differences in resistance are described, what is in consonance with the results found in the present work (Klämpfl et al., 2012; Sedghizadeh et al., 2012).

Regarding the yeast B. bruxellensis, as Fig. 2 shows, it can be said that this microorganism is the most susceptible to plasma treatment compared to both bacteria studied. This is in no consonance with numerous authors who observed a higher resistance of yeast to plasma treatment, what is likely due to its thick and rigid cell wall (Nishime et al., 2017; Sedghizadeh et al., 2012). However, the present findings are consistent with those previous reports which attribute a higher susceptibility of yeast in a food matrix to plasma treatments (Dasan, Boyaci, \& Mutlu, 2017; Thomas-Popo et al., 2019).

Furthermore, both the mechanisms that provoke modifications in microorganisms after APCP treatment and the changes that lead to cell death have been investigated by several researchers (Misra \& Jo, 2017). On the one hand, it is believed that one of the causes of cell damage could be ROS and RNS effect. Some authors suggest that these reactive species could disturb the lipid membrane as a result of the peroxidation of unsaturated fatty acids. Then, modifications of proteins take part due to the amino acids oxidation. The last step is related to an acid nucleic damage, and as a consequence the cell death occurs (Arjunan, Sharma, \& Ptasinska, 2015; Šimončicová et al., 2018; Yong, Kim, Park, Kim, et al., 2015). On the other hand, additional studies have presented a different mechanism for Gram-bacteria damage, associating the one explicated above with Gram + bacteria and yeast. Therefore, when the outer membrane of Gram-acquires enough electric charge its breakage befalls. This process is known as electrostatic disruption and this reasoning could be supported because Gram-bacteria possess an irregular surface which probably makes them more susceptible to that mechanism (Lunov et al., 2016; Mai-Prochnow, Clauson, Hong, \& Murphy, 2016).

Taking into consideration the aforementioned, to understand B. bruxellensis inactivation, it is suggested that the effect of ROS and RNS may induce its death. It should be noted that after the air plasma and nitrogen plasma treatments the best values of inactivation were achieved. When considering the inactivation mechanism for the bacteria studied in this work ( $P$. pentosaceus and A. pasteurianus) it is essential to take into account the differences between both bacteria. The major difference is the characteristics of the cell wall. Firstly, A. pasteurianus possesses an outer membrane so it has a double membrane. Then, $P$. pentosaceus has a murein layer, thicker than the Gram-outer membrane, which makes it more rigid (Sharkey et al., 2015). It is well known that the outer membrane of Gram-consists of phospholipids and lipopolysaccharides while only phospholipids form bacterial cytoplasmatic membrane. Additionally, the position of the membrane lipids, outside of the cell envelope, and the presence of porins give the membrane lipids a weakness when physical stress and morphological changes take place (Mai-Prochnow et al., 2016). Moreover, some researchers found morphological modifications after plasma treatments in Gram- but not in Gram + bacteria, suggesting a lysis in Gram-bacteria due to electrostatic disruption (M. Laroussi \& Leipold, 2004).

In this work, there were found no significant differences about inactivation between both bacteria when air plasma and nitrogen plasma were applied. Consequently, ROS and RNS could be the main mechanism for $P$. pentosaceus and A. pasteurianus reductions after the plasma treatments, as it has been said for the yeast. Notwithstanding, regarding to $A$. pasteurianus, the abovementioned electrostatic disruption may play an important role. However, further investigations should be carried out to identify and define the main causes of bacterial death.

\subsection{Thermal characterization}

With the aim of studying the influence of the temperature in microbial inactivation, wood sample surface temperatures were monitored. In addition, taking into account the importance of the preservation of the functional properties of the oak wood after the plasma treatments, a thermographic study was carried out. Fig. 3 shows the temperature evolution during the 12-passes plasma treatments and the infrared thermographic images according to each plasma gas. Each of the peaks represents each of the plasma passes. As one can see, for all the treatments, the maximum temperature reached during each pass increases slightly as the treatment progresses. This fact is due to the accumulated heat on the sample surface. Related to the plasma gas, the surface temperature of the wood samples exposed to an air plasma reached the highest temperatures for each pass, followed by the nitrogen plasma and the argon plasma. The thermographic images (Fig. 3[a2, b2, c2]) reveal that the increase in temperature on the staves is superficial, so it probably does not affect the functional and bulk properties of the oak wood.

The average and maximum surface temperatures of the wood sample surface during the plasma treatments are shown in Table 2. It is observed that for the air plasma treatments the average and maximum temperatures were the highest and quite similar to the nitrogen plasma ones. By comparison, the argon plasma treatments resulted in the lowest average and maximum surface temperatures. It seems that the higher the plasma power, the greater the reached temperatures on the sample surface.

Several researchers agree about the secondary role of the temperature in microbial inactivation (Ehlbeck et al., 2011; Iuchi et al., 2018). This statement is supported in our work since a similar inactivation was achieved for $P$. pentosaceus regardless of the plasma gas and, therefore, the temperature to which wood samples have been subjected during the plasma treatments. A higher inactivation was achieved in the case of A. pasteurianus when the most energetic plasmas (air and nitrogen) were applied in comparison with the argon plasma treatment. Nevertheless, it is likely due to a greater amount of ROS and RNS that are generated with 

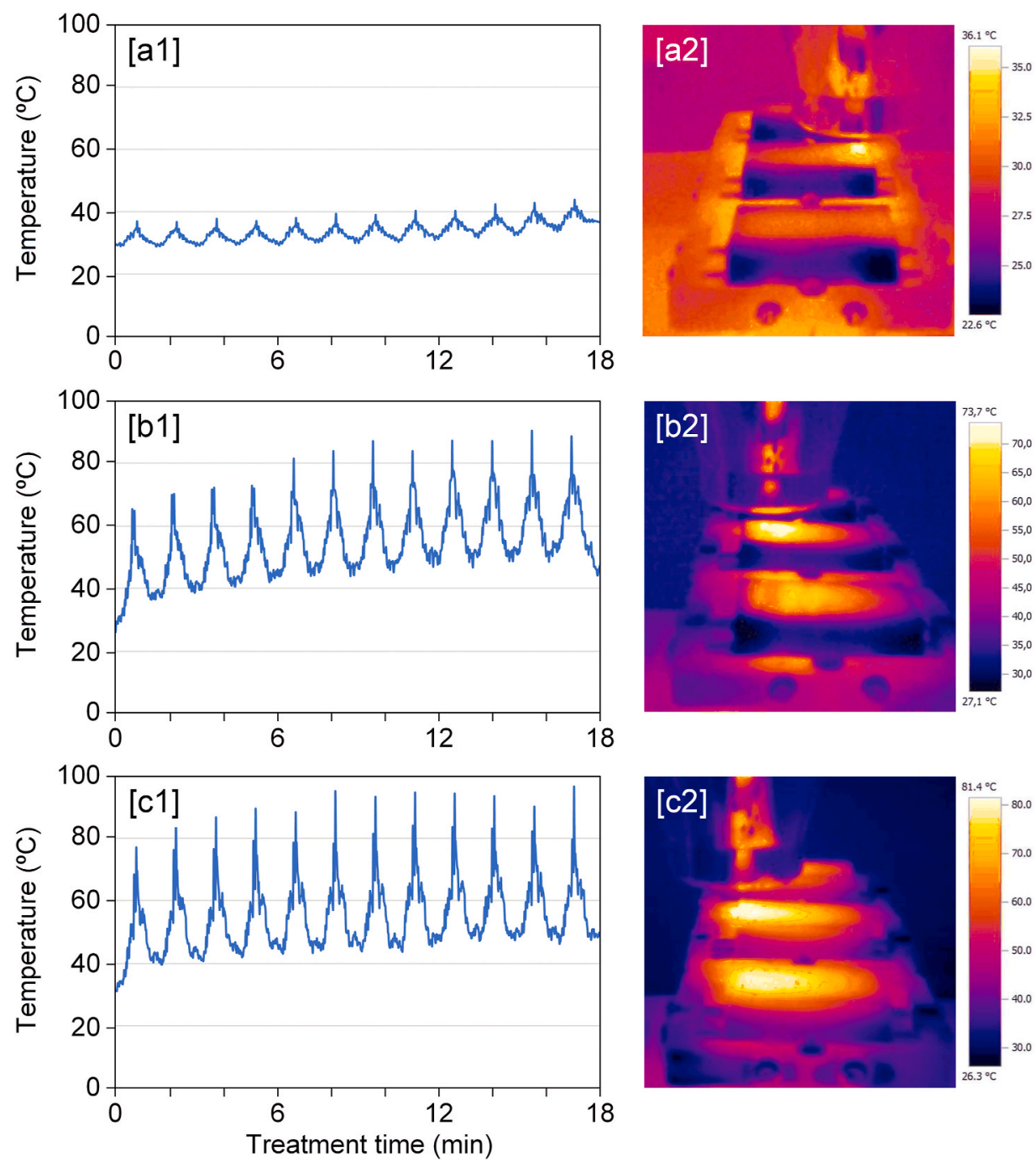

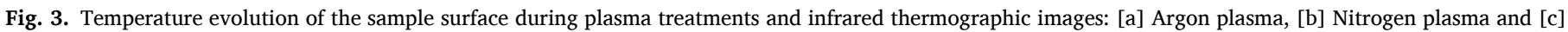
Air plasma.

Table 2

Average and maximum temperatures of the samples during plasma treatments.

\begin{tabular}{llll}
\hline $\begin{array}{l}\text { Sample } \\
\text { label }\end{array}$ & $\begin{array}{l}\text { Plasma } \\
\text { Gas }\end{array}$ & $\begin{array}{l}\text { Average temperature } \\
\left({ }^{\circ} \mathrm{C}\right)\end{array}$ & $\begin{array}{l}\text { Maximum temperature } \\
\left({ }^{\circ} \mathrm{C}\right)\end{array}$ \\
\hline $\mathrm{Ar}$ & Argon & 33.7 & 44.0 \\
$\mathrm{~N}_{2}$ & Nitrogen & 53.0 & 90.3 \\
$\mathrm{Air}$ & Air & 54.3 & 96.3 \\
\hline
\end{tabular}

these kind of plasmas since the role of such reactive species in microbial inactivation seems to be crucial (M. Laroussi \& Leipold, 2004; Niemira, 2012; Reineke et al., 2015). In the case of B. bruxellensis, similarly to A. pasteurianus results, the most energetic plasmas (air and nitrogen) resulted in a higher inactivation. Specifically, a total inactivation was achieved.

Overall, it could be stated that, although thermal differences have been observed between the different plasma treatments, its effect in microbial inactivation does not seem to play a main role.

\subsection{Morphological characterization of the samples}

The surface morphology of the untreated and plasma treated wooden samples were studied by SEM. Fig. 4[a] shows the surface of the untreated sample, describing intact morphology of fiber in oak wood. In addition, the images of the plasma treated samples (Fig. 4[b, c, d]) show a surface with fairly well-defined fibrils. Therefore, it could be concluded that plasma treatment does not damage noticeably the surface of the oak wood samples since no fiber breakage was observed. These observations were consistent with other works (Acda, Devera, Cabangon, \& Ramos, 2012; Novák et al., 2015). As a consequence, it is suggested that the bulk capacity of the oak wood would not be affected (Acda et al., 2012), what would be of great interest for the wine barrel re-using.

\section{Conclusions}

Due to the necessity of new technologies to disinfect wine barrels for its re-using, in the current work, the application of the APCP on the surface of oak wood used in winemaking was studied. Three different gases were used to generate the plasma (air, nitrogen and argon) and three microorganisms were investigated ( $P$. pentosaceus, $A$. pasteurianus and B. bruxellensis).

On the one hand, microorganism type and process parameters (plasma gas and plasma power) had significant effect on the logarithmic reduction. Among the microorganisms, the yeast $B$. bruxellensis was found to be the most sensitive to APCP, achieving total inactivation for the most energetic treatments. Moreover, regarding the plasma gases, air plasma and nitrogen plasma reached similar inactivation values for 

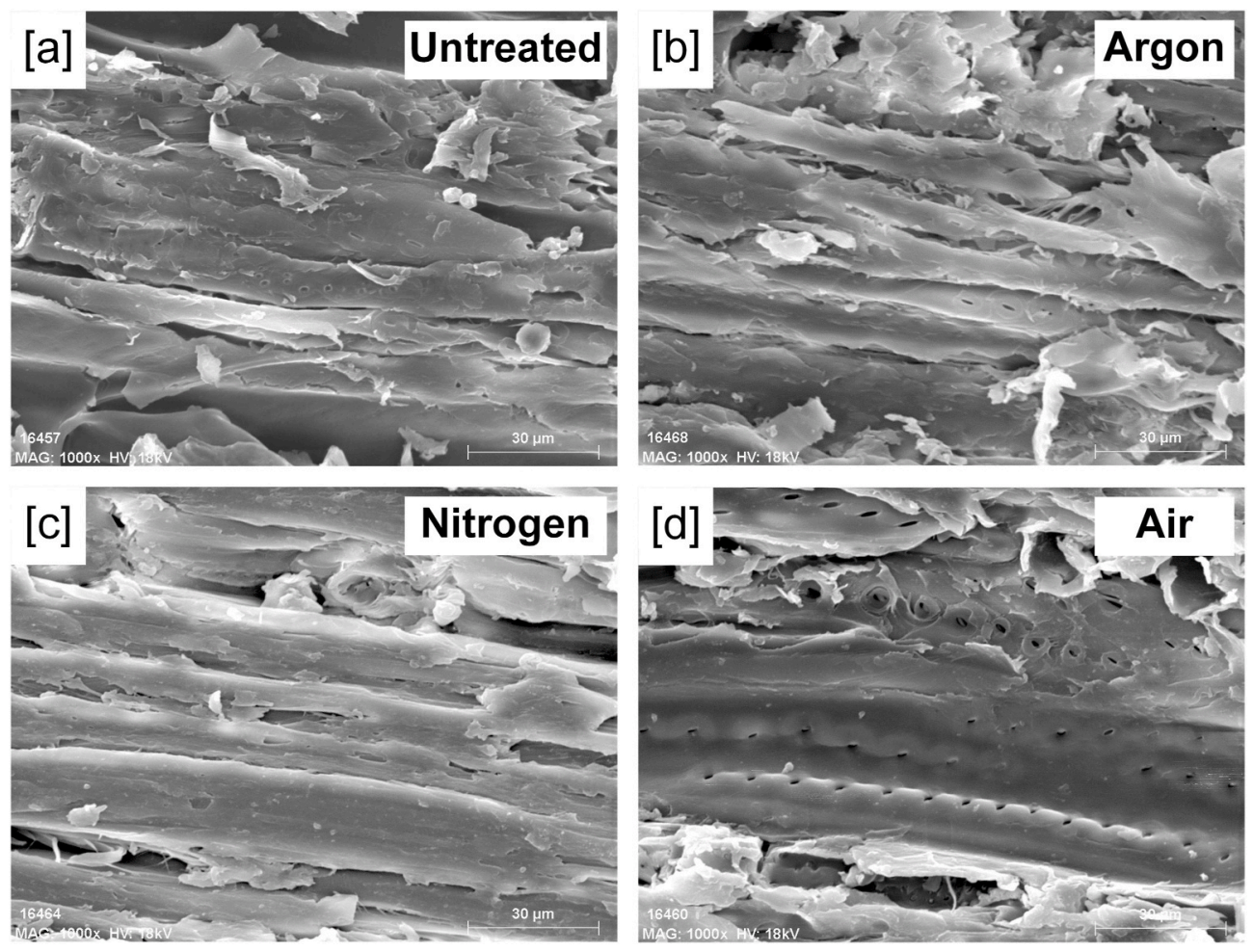

Fig. 4. SEM images of the: [a] untreated sample and samples treated with: [b] Argon plasma, [c] Nitrogen plasma and [d] Air plasma.

each microorganism. Since these results were the best, air plasma and nitrogen plasma were identified as the most effective plasma gases.

On the other hand, it was concluded that the thermal effect is not the main cause why the cell death takes place. Therefore, the effect of reactive species (ROS and RNS) generated during the plasma generation process could play the main role on $B$. bruxellensis inactivation. Last but not least, the data reported by SEM images confirm no morphological modifications on the wood surface after APCP treatment.

In conclusion, based on the above results, APCP is a promising solution to disinfect wine barrels and hence, greatly solve some problems related to their re-using. Further research and investigations will be carried out to achieve the optimal parameters which lead to a total microbial inactivation without affecting both functional wood properties and unique characteristics of each wine. Finally, different studies will be conducted to identify and define the mechanisms of microorganism death.

\section{Funding}

This work was supported by the Ministerio de Economía, Industria y Competitividad of Spain (MINECO) (project PID2019-105367R "Programa Estatal de I + D + i Orientada a los Retos de la Sociedad") and $50 \%$ co-funded by the European Regional Development Fund (FEDER) "A way to make Europe"; and the European Regional Development Fund, granted to the Autonomous Community of La Rioja (project PR07-18), within the 2014-2020 Operational Program. FEDER of La Rioja.

\section{CRediT authorship contribution statement}

Ana Sainz-García: Conceptualization, Methodology, Validation, Formal analysis, Investigation, Data curation, Writing - original draft, Writing - review \& editing. Ana González-Marcos: Conceptualization, Methodology, Validation, Investigation, Data curation, Writing - review \& editing. Rodolfo Múgica-Vidal: Conceptualization, Methodology, Formal analysis, Investigation, Writing - review \& editing. Ignacio Muro-Fraguas: Conceptualization, Methodology, Formal analysis,
Investigation, Data curation, Writing - review \& editing. Rocío Escribano-Viana: Conceptualization, Methodology, Formal analysis, Investigation, Data curation, Writing - original draft, Writing - review \& editing. Lucía González-Arenzana: Conceptualization, Methodology, Formal analysis, Investigation, Resources, Data curation, Writing original draft, Writing - review \& editing. Isabel López-Alfaro: Conceptualization, Methodology, Formal analysis, Investigation, Data curation, Writing - review \& editing. Fernando Alba-Elías: Conceptualization, Methodology, Formal analysis, Investigation, Resources, Data curation, Writing - review \& editing. Elisa Sainz-García: Conceptualization, Methodology, Validation, Formal analysis, Investigation, Data curation, Writing - original draft, Writing - review \& editing.

\section{Declaration of competing interest}

The authors declare that they have no known competing financial interests or personal relationships that could have appeared to influence the work reported in this paper.

\section{Acknowledgements}

The author E. Sainz-García, as postdoctoral researcher of the University of La Rioja, thanks the postdoctoral training program that is funded by the Plan Propio of the University of La Rioja. The author I. Muro-Fraguas, thanks the program of pre-doctoral contracts for the training of research staff funded by the University of La Rioja. The author R. Escribano-Viana thanks the pre-doctoral contract within the State Program for the Promotion of Talent and its Employability of the State Plan for Scientific and Technical Research and Innovation 2013-2016.

\section{References}

Acda, M. N., Devera, E. E., Cabangon, R. J., \& Ramos, H. J. (2012). Effects of plasma modification on adhesion properties of wood. International Journal of Adhesion and Adhesives, 32(1), 70-75. https://doi.org/10.1016/j.ijadhadh.2011.10.003 
Arjunan, K. P., Sharma, V. K., \& Ptasinska, S. (2015). Effects of atmospheric pressure plasmas on isolated and cellular DNA - a review. International Journal of Molecular Sciences, 16(2), 2971-3016. https://doi.org/10.3390/ijms16022971

Bartowsky, E. J. (2009). Bacterial spoilage of wine and approaches to minimize it. Letter in Applied Microbiology, 48(2), 149-156. https://doi.org/10.1111/j.1472 765X.2008.02505.x

Bartowsky, E. J., \& Henschke, P. A. (2008). Acetic acid bacteria spoilage of bottled red wine-A review. International Journal of Food Microbiology, 125(1), 60-70. https://doi. org $/ 10.1016 /$ j.ijfoodmicro.2007.10.016

Chizoba Ekezie, F. G., Sun, D. W., \& Cheng, J. H. (2017). A review on recent advances in cold plasma technology for the food industry: Current applications and future trends. Trends in Food Science \& Technology, 69, 46-58. https://doi.org/10.1016/j. tifs.2017.08.007

Choi, J. H., Han, I., Baik, H. K., Lee, M. H., Han, D.-W., Park, J.-C., et al. (2006). Analysis of sterilization effect by pulsed dielectric barrier discharge. Journal of Electrostatics, 64(1), 17-22. https://doi.org/10.1016/j.elstat.2005.04.001

Clodoveo, M. L., Dipalmo, T., Rizzello, C. G., Corbo, F., \& Crupi, P. (2016). Emerging technology to develop novel red winemaking practices: An overview. Innovative Food Science \& Emerging Technologies, 38, 41-56. https://doi.org/10.1016/j. ifset.2016.08.020

Costantini, A., Cersosimo, M., Del Prete, V., \& Garcia-Moruno, E. (2006). Production of biogenic amines by lactic acid bacteria: Screening by PCR, thin-layer chromatography, and high-performance liquid chromatography of strains isolated from wine and must. Journal of Food Protection, 69(2), 391-396. https://doi.org/ 10.4315/0362-028X-69.2.391

Costantini, A., Vaudano, E., Cravero, M. C., Petrozziello, M., Piano, F., Bernasconi, A. et al. (2016). Dry ice blasting, a new tool for barrel regeneration treatment. European Food Research and Technology, 242(10), 1673-1683. https://doi.org/10.1007/ s00217-016-2667-3

Dasan, B. G., Boyaci, I. H., \& Mutlu, M. (2017). Nonthermal plasma treatment of Aspergillus spp. spores on hazelnuts in an atmospheric pressure fluidized bed plasma system: Impact of process parameters and surveillance of the residual viability of spores. Journal of Food Engineering, 196, 139-149. https://doi.org/10.1016/j. jfoodeng.2016.09.028

Dasan, B. G., Onal-Ulusoy, B., Pawlat, J., Diatczyk, J., Sen, Y., \& Mutlu, M. (2017). A new and simple approach for decontamination of food contact surfaces with gliding arc discharge atmospheric non-thermal plasma. Food and Bioprocess Technology, 10(4), 650-661. https://doi.org/10.1007/s11947-016-1847-2

De Man, J. C., Rogosa, M., \& Sharpe, M. E. (1960). A medium for the cultivation OF lactobacilli. Journal of Applied Bacteriology, 23(1), 130-135. https://doi.org/ 10.1111/j.1365-2672.1960.tb00188.x

Ehlbeck, J., Schnabel, U., Polak, M., Winter, J., Von Woedtke, T., Brandenburg, R., et al. (2011). Low temperature atmospheric pressure plasma sources for microbial decontamination. Journal of Physics D: Applied Physics, 44(1). https://doi.org/ 10.1088/0022-3727/44/1/013002

Falguera, V., Forns, M., \& Ibarz, A. (2013). UV-vis irradiation: An alternative to reduce $\mathrm{SO} 2$ in white wines? Lebensmittel-Wissenschaft und -Technologie-Food Science and Technology, 51(1), 59-64. https://doi.org/10.1016/j.lwt.2012.11.006

Feng, H., Sun, P., Chai, Y., Tong, G., Zhang, J., Zhu, W., et al. (2009). The interaction of a direct-current cold atmospheric-pressure air plasma with bacteria. IEEE Transactions on Plasma Science, 37(1), 121-127. https://doi.org/10.1109/TPS.2008.2008438

Fridman, A. (2008). Plasma chemistry. Plasma Chemistry, 1-978. https://doi.org/ 10.1017/CBO9780511546075, 9780521847.

García-Alcaraz, J. L., Flor Montalvo, F. J., Martínez Cámara, E., Pérez de la Parte, M. M., Jiménez-Macías, E., \& Blanco-Fernández, J. (2020). Economic-environmental impact analysis of alternative systems for red wine ageing in re-used barrels. Journal of Cleaner Production, 244. https://doi.org/10.1016/j.jclepro.2019.118783

González-Arenzana, L., Santamaría, P., López, R., Garijo, P., Gutiérrez, A. R., GardeCerdán, T., et al. (2013). Microwave technology as a new tool to improve microbiological control of oak barrels: A preliminary study. Food Control, 30(2), 536-539. https://doi.org/10.1016/j.foodcont.2012.08.008

Guzzon, R., Bernard, M., Barnaba, C., Bertoldi, D., Pixner, K., \& Larcher, R. (2017). The impact of different barrel sanitation approaches on the spoilage microflora and phenols composition of wine. Journal of Food Science \& Technology, 54(3), 810-821. https://doi.org/10.1007/s13197-017-2527-6

Hertwig, C., Leslie, A., Meneses, N., Reineke, K., Rauh, C., \& Schlüter, O. (2017). Inactivation of Salmonella Enteritidis PT30 on the surface of unpeeled almonds by cold plasma. Innovative Food Science \& Emerging Technologies, 44, 242-248. https:// doi.org/10.1016/j.ifset.2017.02.007

Iuchi, K., Morisada, Y., Yoshino, Y., Himuro, T., Saito, Y., Murakami, T., et al. (2018). Cold atmospheric-pressure nitrogen plasma induces the production of reactive nitrogen species and cell death by increasing intracellular calcium in HEK293T cells. Archives of Biochemistry and Biophysics, 654, 136-145. https://doi.org/10.1016/j. abb.2018.07.015

Kart, D. (2018). Cold Plasma and Ultrasound Applications in Cleaning of Food Contact Surfaces, 4(8), 17-27.

Kim, H. J., Yong, H. I., Park, S., Kim, K., Choe, W., \& Jo, C. (2015). Microbial safety and quality attributes of milk following treatment with atmospheric pressure encapsulated dielectric barrier discharge plasma. Food Control, 47, 451-456. https:// doi.org/10.1016/j.foodcont.2014.07.053

Klämpfl, T. G., Isbary, G., Shimizu, T., Li, Y. F., Zimmermann, J. L., Stolz, W., et al. (2012). Cold atmospheric air plasma sterilization against spores and other microorganisms of clinical interest. Applied and Environmental Microbiology, 78(15), 5077-5082. https://doi.org/10.1128/AEM.00583-12

Kondeti, V. S. S. K., Phan, C. Q., Wende, K., Jablonowski, H., Gangal, U., Granick, J. L., et al. (2018). Long-lived and short-lived reactive species produced by a cold atmospheric pressure plasma jet for the inactivation of Pseudomonas aeruginosa and Staphylococcus aureus. Free Radical Biology and Medicine, 124, 275-287. https://doi. org/10.1016/j.freeradbiomed.2018.05.083

Laroussi, M. (2005). Low temperature plasma-based sterilization: Overview and state-ofthe-art. Plasma Processes and Polymers, 2(5), 391-400. https://doi.org/10.1002/ ppap. 200400078

Laroussi, M., \& Leipold, F. (2004). Evaluation of the roles of reactive species, heat, and UV radiation in the inactivation of bacterial cells by air plasmas at atmospheric pressure. International Journal of Mass Spectrometry, 233(1-3), 81-86. https://doi. org/10.1016/j.ijms.2003.11.016

Lee, H. J., Jung, H., Choe, W., Ham, J. S., Lee, J. H., \& Jo, C. (2011). Inactivation of Listeria monocytogenes on agar and processed meat surfaces by atmospheric pressure plasma jets. Food Microbiology, 28(8), 1468-1471. https://doi.org/ 10.1016/j.fm.2011.08.002

Liu, H., Chen, J., Yang, L., \& Zhou, Y. (2008). Long-distance oxygen plasma sterilization: Effects and mechanisms. Applied Surface Science, 254(6), 1815-1821. https://doi. org/10.1016/j.apsusc.2007.07.152

Lotfy, K., Al-Harbi, N. A., \& Abd El-Raheem, H. (2019). Cold atmospheric pressure nitrogen plasma jet for enhancement germination of wheat seeds. Plasma Chemistry and Plasma Processing, 39(4), 897-912. https://doi.org/10.1007/s11090-019-09969-

Lunov, O., Zablotskii, V., Churpita, O., Jäger, A., Polívka, L., Syková, E., et al. (2016). The interplay between biological and physical scenarios of bacterial death induced by non-thermal plasma. Biomaterials, 82, 71-83. https://doi.org/10.1016/j. biomaterials.2015.12.027

Mai-Prochnow, A., Clauson, M., Hong, J., \& Murphy, A. B. (2016). Gram positive and Gram negative bacteria differ in their sensitivity to cold plasma. Scientific Reports, 6 (December), 1-11. https://doi.org/10.1038/srep38610

Mai-Prochnow, A., Murphy, A. B., McLean, K. M., Kong, M. G., \& Ostrikov, K. (2014) Atmospheric pressure plasmas: Infection control and bacterial responses. International Journal of Antimicrobial Agents, 43(6), 508-517. https://doi.org/ 10.1016/j.ijantimicag.2014.01.025

Mandal, R., Singh, A., \& Pratap Singh, A. (2018). Recent developments in cold plasma decontamination technology in the food industry. Trends in Food Science \& Technology, 80, 93-103. https://doi.org/10.1016/j.tifs.2018.07.014

Marko, S. D., Dormedy, E. S., Fugelsang, K. C., Dormedy, D. F., Gump, B., \& Wample, R. L. (2005). Analysis of oak volatiles by gas chromatography-mass spectrometry after ozone sanitization. American Journal of Enology and Viticulture, 56 (1), 46-51.

Miao, H., \& Jierong, C. (2009). Inactivation of Escherichia coli and properties of medical poly(vinyl chloride) in remote-oxygen plasma. Applied Surface Science, 255(11), 5690-5697. https://doi.org/10.1016/j.apsusc.2008.12.056

Misra, N. N., \& Jo, C. (2017). Applications of cold plasma technology for microbiological safety in meat industry. Trends in Food Science \& Technology, 64, 74-86. https://doi. org/10.1016/j.tifs.2017.04.005

Misra, N. N., Patil, S., Moiseev, T., Bourke, P., Mosnier, J. P., Keener, K. M., et al. (2014). In-package atmospheric pressure cold plasma treatment of strawberries. Journal of Food Engineering, 125(1), 131-138. https://doi.org/10.1016/j.jfoodeng. 2013.10.023

Misra, N. N., Yepez, X., Xu, L., \& Keener, K. (2019). In-package cold plasma technologies. Journal of Food Engineering, 244(September 2018), 21-31. https://doi.org/10.1016/ j.jfoodeng.2018.09.019

Mošovská, S., Medvecká, V., Gregová, M., Tomeková, J., Valík, Ľ., Mikulajová, A., et al. (2019). Plasma inactivation of Aspergillus flavus on hazelnut surface in a diffuse barrier discharge using different working gases. Food Control, 104(March), 256-261. https://doi.org/10.1016/j.foodcont.2019.05.003

Muranyi, P., Wunderlich, J., \& Heise, M. (2008). Influence of relative gas humidity on the inactivation efficiency of a low temperature gas plasma. Journal of Applied Microbiology, 104(6), 1659-1666. https://doi.org/10.1111/j.13652672.2007.03691.x

Niemira, B. A. (2012). Cold plasma reduction of Salmonella and Escherichia coli O157: H7 on almonds using ambient pressure gases. Journal of Food Science, 77(3), 171-175. https://doi.org/10.1111/j.1750-3841.2011.02594.x

Nishime, T. M. C., Borges, A. C., Koga-Ito, C. Y., Machida, M., Hein, L. R. O., \& Kostov, K. G. (2017). Non-thermal atmospheric pressure plasma jet applied to inactivation of different microorganisms. Surface and Coatings Technology, 312, 19-24. https://doi.org/10.1016/j.surfcoat.2016.07.076

Novák, I., Popelka, A., Špitalský, Z., Mičušík, M., Omastová, M., Valentin, M., et al. (2015). Investigation of beech wood modified by radio-frequency discharge plasma. Vacuum, 119, 88-94. https://doi.org/10.1016/j.vacuum.2015.04.038

Paixão, L. M. N., Fonteles, T. V., Oliveira, V. S., Fernandes, F. A. N., \& Rodrigues, S. (2019). Cold plasma effects on functional compounds of siriguela juice. Food and Bioprocess Technology, 12(1), 110-121. https://doi.org/10.1007/s11947-018-2197-z

Palacios, A., Borinaga, I., \& Carrillo, D. (2012). Estudio comparativo de sistemas de desinfección de barricas de vino como alternativas al empleo del sulfuroso. Enólogos, 77, 46-54.

Park, S. Y., \& Ha, S. D. (2018). Assessment of cold oxygen plasma technology for the inactivation of major foodborne viruses on stainless steel. Journal of Food Engineering, 223, 42-45. https://doi.org/10.1016/j.jfoodeng.2017.11.041

Porter, G. W., Lewis, A., Barnes, M., \& Williams, R. (2011). Evaluation of high powe ultrasound porous cleaning efficacy in American oak wine barrels using X-ray tomography. Innovative Food Science \& Emerging Technologies, 12(4), 509-514. https://doi.org/10.1016/j.ifset.2011.06.007

Reineke, K., Langer, K., Hertwig, C., Ehlbeck, J., \& Schlüter, O. (2015). The impact of different process gas compositions on the inactivation effect of an atmospheric pressure plasma jet on Bacillus spores. Innovative Food Science \& Emerging Technologies, 30, 112-118. https://doi.org/10.1016/j.ifset.2015.03.019 
Ribéreau-Garyon, P., Glories, Y., Maujean, A., \& Dubourdieu, D. (2006). Handbook of enology.

Schmid, F., Grbin, P., Yap, A., \& Jiranek, V. (2011). Relative efficacy of high-pressure hot water and high-power ultrasonics for wine oak barrel sanitization. American Journal of Enology and Viticulture, 62(4), 519-526. https://doi.org/10.5344/ ajev.2011.11014

Schmidt-Bleker, A., Winter, J., Bösel, A., Reuter, S., \& Weltmann, K. D. (2015). On the plasma chemistry of a cold atmospheric argon plasma jet with shielding gas device. Plasma Sources Science and Technology, 25(1). https://doi.org/10.1088/0963-0252/ 25/1/015005

Scholtz, V., Pazlarova, J., Souskova, H., Khun, J., \& Julak, J. (2015). Nonthermal plasma - a tool for decontamination and disinfection. Biotechnology Advances, 33(6), 1108-1119. https://doi.org/10.1016/j.biotechadv.2015.01.002

Sedghizadeh, P. P., Chen, M. T., Schaudinn, C., Gorur, A., \& Jiang, C. (2012). Inactivation kinetics study of an atmospheric-pressure cold-plasma jet against pathogenic microorganisms. IEEE Transactions on Plasma Science, 40(11 PART1), 2879-2882 https://doi.org/10.1109/TPS.2012.2213306

Seo, Y. S., Mohamed, A. A. H., Woo, K. C., Lee, H. W., Lee, J. K., \& Kim, K. T. (2010). Comparative studies of atmospheric pressure plasma characteristics between He and Ar working gases for sterilization. IEEE Transactions on Plasma Science, 38(10 PART 2), 2954-2962. https://doi.org/10.1109/TPS.2010.2058870

Sharkey, M. A., Chebbi, A., McDonnell, K. A., Staunton, C., \& Dowling, D. P. (2015). Evaluation of the sensitivity of bacterial and yeast cells to cold atmospheric plasma jet treatments. Biointerphases, 10(2), Article 029507. https://doi.org/10.1116/ 1.4916928

Šimončicová, J., Kaliňáková, B., Kováčik, D., Medvecká, V., Lakatoš, B., Kryštofová, S., et al. (2018). Cold plasma treatment triggers antioxidative defense system and induces changes in hyphal surface and subcellular structures of Aspergillus flavus. Applied Microbiology and Biotechnology, 102(15), 6647-6658. https://doi.org/ 10.1007/s00253-018-9118-y

Stadler, E., Schmarr, H. G., \& Fischer, U. (2020). Influence of physical and chemical barrel sanitization treatments on the volatile composition of toasted oak wood. European Food Research and Technology, 246(3), 497-511. https://doi.org/10.1007/ s00217-019-03417-7

Suárez, R., Suárez-Lepe, J. A., Morata, A., \& Calderón, F. (2007). The production of ethylphenols in wine by yeasts of the genera Brettanomyces and Dekkera: A review. Food Chemistry, 102(1), 10-21. https://doi.org/10.1016/j.foodchem.2006.03.030

Surowsky, B., Fröhling, A., Gottschalk, N., Schlüter, O., \& Knorr, D. (2014). Impact of cold plasma on Citrobacter freundii in apple juice: Inactivation kinetics and mechanisms. International Journal of Food Microbiology, 174, 63-71. https://doi.org/ 10.1016/j.ijfoodmicro.2013.12.031
Thomas-Popo, E., Mendonça, A., Misra, N. N., Little, A., Wan, Z., Moutiq, R., et al. (2019). Inactivation of Shiga-toxin-producing Escherichia coli, Salmonella enterica and natural microflora on tempered wheat grains by atmospheric cold plasma. Food Control, 104(December 2018), 231-239. https://doi.org/10.1016/j. foodcont.2019.04.025

Tolouie, H., Mohammadifar, M. A., Ghomi, H., Yaghoubi, A. S., \& Hashemi, M. (2018). The impact of atmospheric cold plasma treatment on inactivation of lipase and lipoxygenase of wheat germs. Innovative Food Science \& Emerging Technologies, 47 (April), 346-352. https://doi.org/10.1016/j.ifset.2018.03.002

Wan, Z., Chen, Y., Pankaj, S. K., \& Keener, K. M. (2017). High voltage atmospheric cold plasma treatment of refrigerated chicken eggs for control of Salmonella Enteritidis contamination on egg shell. Lebensmittel-Wissenschaft und -Technologie- Food Science and Technology, 76, 124-130. https://doi.org/10.1016/j.lwt.2016.10.051

Wiegand, C., Beier, O., Horn, K., Pfuch, A., Tölke, T., Hipler, U. C., et al. (2013). Antimicrobial impact of cold atmospheric pressure plasma on medical critical yeasts and bacteria cultures. Skin Pharmacology and Physiology, 27(1), 25-35. https://doi. org/10.1159/000351353

Xiao, D., Cheng, C., Lan, Y., Ni, G. H., Shen, J., Meng, Y. D., et al. (2016). Effects of atmospheric-pressure nonthermal nitrogen and air plasma on bacteria inactivation. IEEE Transactions on Plasma Science, 44(11), 2699-2707. https://doi.org/10.1109/ TPS.2016.2598564

Yodpitak, S., Mahatheeranont, S., Boonyawan, D., Sookwong, P., Roytrakul, S., \& Norkaew, O. (2019). Cold plasma treatment to improve germination and enhance the bioactive phytochemical content of germinated brown rice. Food Chemistry, 289 (September 2018), 328-339. https://doi.org/10.1016/j.foodchem.2019.03.061

Yong, H. I., Kim, H. J., Park, S., Alahakoon, A. U., Kim, K., Choe, W., et al. (2015a). Evaluation of pathogen inactivation on sliced cheese induced by encapsulated atmospheric pressure dielectric barrier discharge plasma. Food Microbiology, 46, 46-50. https://doi.org/10.1016/j.fm.2014.07.010

Yong, H. I., Kim, H. J., Park, S., Kim, K., Choe, W., Yoo, S. J., et al. (2015b). Pathogen inactivation and quality changes in sliced cheddar cheese treated using flexible thinlayer dielectric barrier discharge plasma. Food Research International, 69, 57-63. https://doi.org/10.1016/j.foodres.2014.12.008

Yoon, S. Y., Kim, K. H., Seol, Y. J., Kim, S. J., Bae, B., Huh, S. R., et al. (2016). Effects of metastable species in helium and argon atmospheric pressure plasma jets (APPJs) on inactivation of periodontopathogenic bacteria. Journal of the Korean Physical Society, 68(10), 1176-1191. https://doi.org/10.3938/jkps.68.1176

Ziuzina, D., Patil, S., Cullen, P. J., Keener, K. M., \& Bourke, P. (2014). Atmospheric cold plasma inactivation of Escherichia coli, Salmonella enterica serovar Typhimurium and Listeria monocytogenes inoculated on fresh produce. Food Microbiology, 42, 109-116. https://doi.org/10.1016/j.fm.2014.02.007 